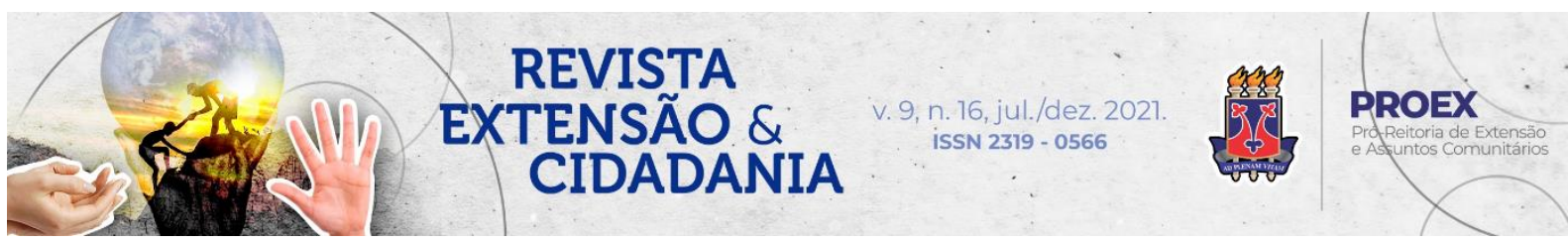

DOI: 10.22481/recuesb.v9i16.9505

\title{
USO DE METODOLOGIA ATIVA E TECNOLOGIAS DIGITAIS PARA FABRICAÇÃO DE INSTRUMENTOS MUSICAIS COM RESÍDUOS SÓLIDOS
}

\author{
USE OF ACTIVE METHODOLOGY AND DIGITAL TECHNOLOGIES FOR \\ MANUFACTURING MUSICAL INSTRUMENTS WITH SOLID WASTE
}

\author{
USO DE METODOLOGÍA ACTIVA Y TECNOLOGÍAS DIGITALES PARA LA \\ FABRICACIÓN DE INSTRUMENTOS MUSICALES CON RESIDUOS SÓLIDOS
}

Juliano da Cunha Gomes ${ }^{1}$

\begin{abstract}
Resumo: O modelo social e econômico linear atual baseado na extração, consumo e descarte contribuiu em nível global para que a geração e consequente disposição de resíduos em aterros aumentasse ao longo dos anos. No Brasil, a Política Nacional de Resíduos Sólidos (PNRS) orienta que seja observada a seguinte ordem de prioridade na gestão de Resíduos Sólidos Urbanos (RSU): não geração, redução, reutilização, reciclagem, tratamento dos resíduos sólidos e disposição final ambientalmente adequada dos rejeitos. Em 2019, foram geradas no país 79 milhões de toneladas de RSU e a maior parte desse montante foi aterrado, indicando, entre as diversas demandas, a necessidade de campanhas de educação ambiental para a reutilização de resíduos de forma a atender às orientações da PNRS. Por isso, esse projeto abordou o uso de tecnologias digitais e metodologia baseada em projeto com estudantes do curso Superior de Tecnologia em Gestão Ambiental do IFSC de Garopaba/SC durante a fase de atividades não presenciais em decorrência da pandemia causada pelo Sars-Covid-19, através da realização de um projeto de extensão com o objetivo de qualificar na comunidade fabricadores de instrumentos musicais a partir da reutilização de RSU. Ao todo foram produzidos 8 vídeos, as lives tiveram um pico simultâneo médio de 30 pessoas e até o momento da conclusão deste trabalho os 8 vídeos somavam 486 visualizações. Os resultados obtidos foram altamente positivos e demonstraram que é imprescindível o olhar institucional para o melhoramento de sua infraestrutura e capacitação contínua da comunidade acadêmica no uso de metodologias ativas e tecnologias digitais.
\end{abstract}

Palavras-chave: Resíduos Sólidos Urbanos. Tecnologias digitais. Metodologia ativa.

Abstract: The current linear social and economic model based on extraction, consumption and disposal has contributed at a global level so that the generation and consequent disposal of waste in landfills has increased over the years. In Brazil, the National Solid Waste Policy (PNRS) advises that the following priority order be observed in the management of Urban Solid Waste (RSU): non-generation, reduction, reuse, recycling, treatment of solid waste and environmentally adequate final disposal of waste. In 2019, 79 million tons of MSW were

1 Engenheiro Ambiental. Doutor em Engenharia Ambiental, pela Universidade Federal de Santa Catarina. Professor do Instituto Federal de Santa Catarina, Campus Garopaba, Santa Catarina, Brasil. Orcid: https://orcid.org/0000-0003-0312-4933Ｅ-mail: juliano.gomes@ifsc.edu.br 
generated in the country and most of this amount was filled, indicating, among the various demands, the need for environmental education campaigns for the reuse of waste in order to meet the guidelines of the PNRS. Therefore, this project addressed the use of digital technologies and project-based methodology with students from the Environmental Management Technology course at IFSC in Garopaba/SC during the off-site activities phase due to the pandemic caused by Sars-Covid-19, through the realization of a project extension program with the objective of qualifying musical instrument manufacturers from the reuse of $R S U$ in the community. In all, eight videos were produced. Lives had an average simultaneous peak of 30 people and by the time this work was completed, the eight videos totaled 486 views. The results obtained were highly positive and demonstrated that an institutional perspective is essential for the improvement of its infrastructure and continuous training of the academic community in the use of active methodologies and digital technologies.

Keywords: Municipal solid waste. Digital technologies. Active methodology.

Resumen: El actual modelo lineal social y económico basado en la extracción, consumo y disposición ha contribuido a nivel global a que la generación y consecuente disposición de residuos en vertederos se haya incrementado a lo largo de los años. En Brasil, la Política Nacional de Residuos Sólidos (PNRS) aconseja que se observe el siguiente orden de prioridad en la gestión de Residuos Sólidos Urbanos (RSU): no generación, reducción, reutilización, reciclaje, tratamiento de residuos sólidos y disposición final ambientalmente adecuada de residuos. En 2019 se generaron 79 millones de toneladas de RSU en el país y la mayor parte de esta cantidad se cubrió, lo que indica, entre las diversas demandas, la necesidad de campañas de educación ambiental para la reutilización de residuos para cumplir con los lineamientos del PNRS. Por lo tanto, este proyecto abordó el uso de tecnologías digitales y metodología basada en proyecto con estudiantes del curso de Tecnología de Gestión Ambiental en IFSC en Garopaba / SC durante la fase de actividades fuera del sitio debido a la pandemia causada por Sars-Covid-19, mediante la realización de un programa de extensión del proyecto con el objetivo de calificar a los fabricantes de instrumentos musicales de la reutilización de $R S U$ en la comunidad. En total, se produjeron 8 videos. Las vidas tuvieron un pico simultáneo promedio de 30 personas y cuando se completó este trabajo, los 8 videos totalizaron 486 visitas. Los resultados obtenidos fueron altamente positivos y demostraron que una perspectiva institucional es fundamental para el mejoramiento de su infraestructura y la formación continua de la comunidad académica en el uso de metodologías activas y tecnologías digitales. Palabras clave: Residuos Sólidos Urbanos. Tecnologías digitales. Metodología activa.

\section{Introdução}

A Política Nacional de Resíduos Sólidos (PNRS) orienta que seja observada a seguinte ordem de prioridade na gestão dos Resíduos Sólidos Urbanos (RSU): não geração, redução, reutilização, reciclagem, tratamento dos resíduos sólidos e disposição final ambientalmente adequada dos rejeitos, ou seja, existe a necessidade de implementação de campanhas de educação ambiental com a população para não geração, redução, reutilização e reciclagem dos

Revista Extensão \& Cidadania, v. 9, n. 16, p. 95-111, jul./dez. 2021.

ISSN 2319-0566 DOI: 10.22481/recuesb.v9i16.9505 
RSU, sendo a destinação final em aterros a última opção adotada e apenas para os rejeitos (aquilo que não há tratamento em face das tecnologias disponíveis), entretanto na prática observa-se justamente o contrário (BRASIL, 2010).

Em 2019, foram geradas no Brasil 79 milhões de toneladas de RSU, deste montante, $59,5 \%$ foram destinados aos aterros sanitários e 40,5\% foram para locais inadequados, como os aterros controlados e lixões. A composição gravimétrica dos RSU no país foi de 3\% para o vidro; 3\% para metal; $9 \%$ para papel/papelão; $13 \%$ para o plástico; $22 \%$ para outros e $50 \%$ para os resíduos orgânicos (ABRELPE, 2020; BRASIL, 2011).

Garopaba, por exemplo, é um município turístico no Centro do Estado de Santa Catarina, com 115,405 km² de extensão, população estimada em 23.579 habitantes, inserido na Área de Proteção Ambiental (APA) da baleia-franca e com proximidade com outras Unidades de Conservação federais. Além disso, não possui sistema público de coleta e tratamento de esgotos, na área urbana, na maioria dos casos, o esgoto sanitário é disposto em fossas sépticas, em alguns casos é realizada a ligação direta nos corpos hídricos existentes e no sistema de drenagem do município. $\mathrm{Na}$ alta temporada do ano de 2017, a geração de RSU do município foi de 1.500 ton/mês e, na baixa temporada, a geração foi de 800 ton/mês, representando uma geração média per capita de 1,18 kg/hab.dia na baixa temporada, ou seja, maior do que a média nacional de $1 \mathrm{~kg} / \mathrm{hab}$.dia. O município não dispõe de coleta seletiva, sistema de compostagem ou programas de educação ambiental, enviando todo o seu RSU para aterros e possui um lixão não remediado (GAROPABA, 2012, 2018, 2021; IBGE, 2020; SALVADOR, 2012).

Devido à cidade de Garopaba ser um lugar com praias, há ainda o agravante dos RSU que acabam no mar, gerando impactos adversos à fauna e à flora marinha. Entre os principais resíduos provenientes de fontes terrestres encontrados no mar, pode-se citar grande quantidade de garrafas e embalagens de alimento recentemente descartadas, canudos para bebidas e "bitucas de cigarro". Os dez tipos de resíduos mais encontrados nas praias em 2018, por ordem de grandeza foram: "bitucas de cigarros"; embalagens de alimentos; garrafas plásticas; tampas de garrafas plásticas; sacolas plásticas; outros sacos plásticos; canudos e agitadores de bebidas; embalagens plásticas de alimentos; outras tampas plásticas e embalagens de EPS (TURRA et al., 2020).

Esse panorama de geração e disposição de resíduos em aterros, que vem aumentando ao longo dos anos, foi consequência do modelo social e econômico linear atual baseado na extração, consumo e descarte. Por isso, percebe-se a necessidade de adotar medidas favoráveis

Revista Extensão \& Cidadania, v. 9, n. 16, p. 95-111, jul./dez. 2021.

ISSN 2319-0566 DOI: 10.22481/recuesb.v9i16.9505 
ao uso mais eficiente dos bens, incluindo a incorporação dos resíduos sólidos no ciclo de vida dos produtos. Neste contexto, a economia circular é um modelo econômico não linear baseado na prevenção, redução, reutilização, recuperação e reciclagem de materiais e energia, que substitui o conceito de "fim de vida" da economia linear por fluxos circulares de reutilização, restauração e renovação, num processo integrado, sendo elemento fundamental na promoção da dissociação entre a ideia de que o crescimento econômico está atrelada ao aumento no consumo de recursos naturais (COSENZA; ANDRADE; ASSUNÇÃO, 2020; PORTUGAL, 2017).

A reutilização e reciclagem de resíduos como peça da economia circular pode começar na escola e expandir-se para a comunidade externa através de projetos de extensão, reciclando resíduos orgânicos, produzindo artesanatos e instrumentos musicais a partir de RSU por exemplo, de forma presencial ou online. Ambos os formatos possuem vantagens e desvantagens, mas o formato online passou a ser uma realidade diante da fase de distanciamento social da pandemia causada pelo Sars-Covid-19 que, além de possibilitar a troca de saberes e experiências, permite as pessoas se qualificarem a qualquer momento, uma vez que o percurso formativo esteja disponível na Internet (GALLO; GUENTHER, 2015; GOMES, 2021; OLIVEIRA et al., 2007).

Por isso, a participação efetiva dos estudantes em projetos no formato online pressupõe o uso de metodologias ativas e tecnologias digitais. Neste sentido, o estudante passa a ser o centro do processo educativo, ouvindo, vendo, perguntando, discutindo, fazendo e ensinando, ou seja, um agente autônomo capaz de construir conhecimento, examinar situações, refletir, resolver problemas de maneira a fomentar o seu próprio desenvolvimento. Entre as metodologias ativas pode-se citar a instrução por pares, aprendizagem baseada em problemas, aula invertida, aprendizagem baseada em projeto, aprendizagem baseada em equipe, escrita por meio das disciplinas e o estudo de caso (CASTAMAN; BORTOLI, 2021; MORAN, 2015).

Já as tecnologias digitais são um conjunto de recursos disponíveis nos dispositivos eletrônicos baseados em linguagem com códigos binários, que permitem informar, comunicar, interagir e aprender. Consequentemente, possibilitam o registro, visualização e a percepção do processo de aprendizagem de cada um e de todos os envolvidos, potencializando o uso das metodologias, sejam elas ativas ou não. Pode-se exemplificar como recursos das tecnologias digitais o uso de dispositivos desktop ou móveis como computadores, tablets e telefones celulares, uso de processadores de texto, planilhas eletrônicas, apresentação de slides,

Revista Extensão \& Cidadania, v. 9, n. 16, p. 95-111, jul./dez. 2021.

ISSN 2319-0566 DOI: 10.22481/recuesb.v9i16.9505 
formulários online, produção e uso de imagens e vídeos, o uso de redes sociais, uso aplicativos para videochamadas com ou sem transmissão de lives para o YouTube entre outros (FERRARINI; SAHEB; TORRES, 2019; MORAN, 2015).

Dessa forma, esse trabalho abordou o uso de tecnologias digitais e metodologia baseada em projeto com os estudantes do Curso Superior de Tecnologia em Gestão Ambiental, do Instituto Federal de Santa Catarina (IFSC), Campus Garopaba, Santa Catarina, com o objetivo de qualificar fabricadores de instrumentos musicais a partir da reutilização de RSU na comunidade de Garopaba/SC, durante a fase de distanciamento social da pandemia causada pelo Sars-Covid-19, através de um projeto de extensão. Para tanto foi necessário: 1) Realizar pesquisa na Internet para definir quais instrumentos musicais eram possíveis de construir em casa; 2) Produzir vídeos usando um padrão de filmagem pré-estabelecido; 3) Divulgar o projeto na comunidade através das redes sociais do IFSC e 4) Realizar a formação da comunidade externa através de três lives.

\section{Metodologia}

Esta ação de extensão foi submetida e aprovada no formato projeto, através de edital interno, acontecendo de forma não presencial entre dezembro de 2020 e agosto de 2021 no Laboratório de Tecnologias Ambientais (LATA), do Curso Superior de Tecnologia em Gestão Ambiental, do Instituto Federal de Santa Catarina (IFSC), Campus Garopaba, e contou com um professor coordenador, duas estudantes do curso e um membro da Coordenadoria de Relações Externas (CERE) do Campus.

Utilizou-se a metodologia baseada projeto com as estudantes para a produção de vídeos e lives, como ferramenta de planejamento, o Trello, organizando os fluxos das atividades realizadas através do sistema Kanban (Figura 2). Ou seja, dividiu-se as atividades em três quadros (não iniciado, em execução e concluído) e em cada quadro adicionou-se cartões com a descrição das tarefas, checklist de atividades prazo de entrega e prioridade de entrega com cores (Figura 1). A medida em que as atividades foram concluídas, os cartões eram movidos para o quadro seguinte.

Revista Extensão \& Cidadania, v. 9, n. 16, p. 95-111, jul./dez. 2021.

ISSN 2319-0566 DOI: 10.22481/recuesb.v9i16.9505 
Figura 2 - Fluxo das atividades do projeto no Trello usando o sistema Kanban

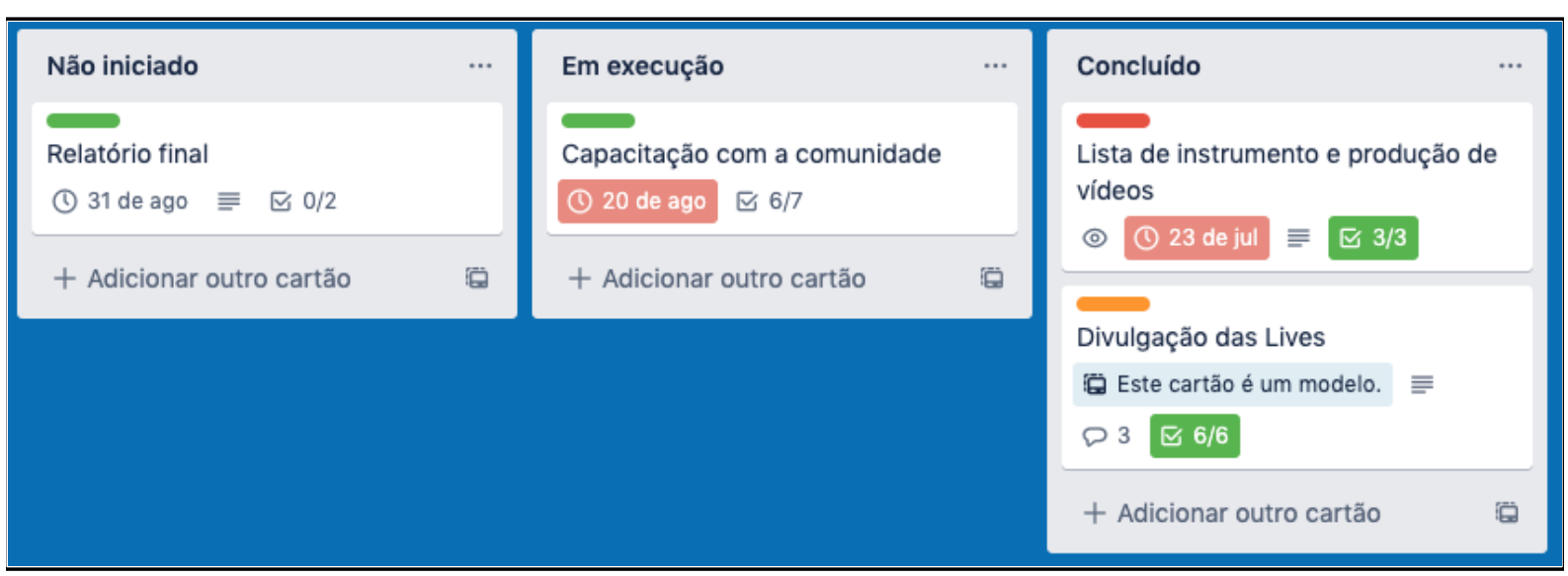

Fonte: Elaborada pelo autor.

Figura 1 - Exemplo de cartão com atividades

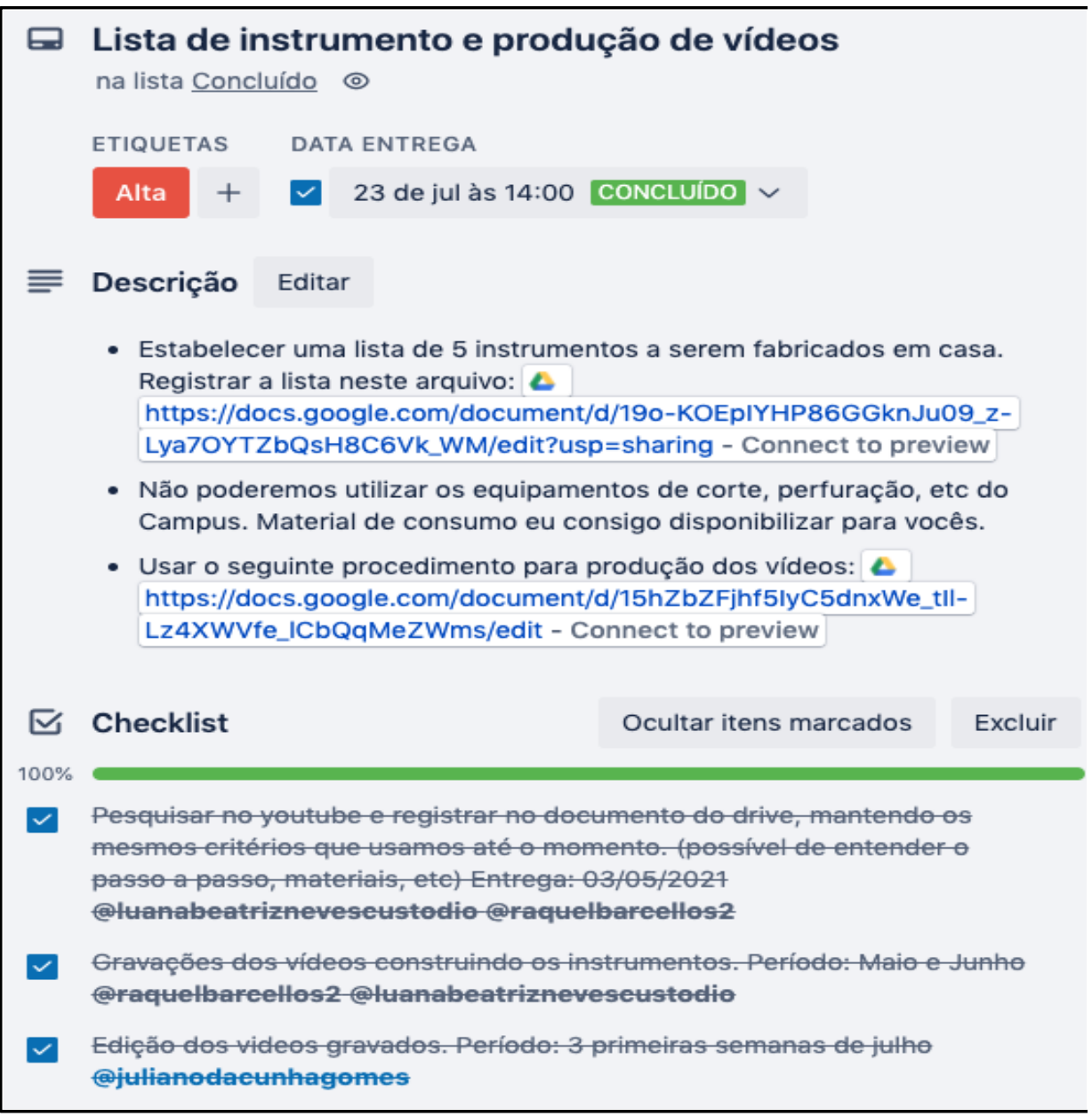

Fonte: Elaborada pelo autor.

Revista Extensão \& Cidadania, v. 9, n. 16, p. 95-111, jul./dez. 2021.

ISSN 2319-0566 DOI: 10.22481/recuesb.v9i16.9505 
Utilizou-se, também, videochamadas e troca de mensagens por grupo de WhatsApp realizadas periodicamente para atualizar as atividades no Trello e manter todos informados. As estudantes estavam responsáveis pela maior parte das atividades, sob a coordenação do docente. Todas as atividades foram registradas.

A primeira etapa da execução do projeto foi a realização de pesquisa pela Internet para definir os instrumentos musicais a serem construídos a partir de resíduos sólidos. Para tanto, as estudantes realizaram pesquisa no YouTube durante três meses, com a finalidade de encontrar vídeos de instrumentos possíveis de serem adaptados e construídos em casa com os resíduos disponíveis e ferramentas simples. Os resultados da pesquisa foram registrados em um documento no Google Drive.

Na segunda etapa, elaborou-se os vídeos da construção dos instrumentos, esta etapa teve duração de três meses e os vídeos foram produzidos pelas estudantes em suas casas. Usaram resíduos como matéria prima, telefone celular para a gravação dos vídeos, computador e aplicativo de edição de vídeo para realizar recortes de cenas, inserção de textos, legendas e música de fundo, de modo a manter uma duração média de 10 minutos cada vídeo. Com a intenção de orientar as estudantes na padronização do método de construção dos instrumentos em casa, gravações dos vídeos e qualidade da captura do áudio e vídeo, foi proposto o procedimento do Quadro 1.

\section{Quadro 1 - Procedimentos para a gravação dos vídeos em casa}

\section{Procedimentos para a gravação dos vídeos em casa}

1. Posicionar a câmera em local com bastante iluminação e fundo claro (mesa ou toalha clara), ou com fundo que contraste com os materiais de forma a ficar bem visível no vídeo.

2. A Câmera precisa estar fixa (parada), sem possibilidade de vibração, posicionada de frente para a atividade, igual a esse vídeo. Se não tiver um suporte específico para a câmera, inventar um que possa ser utilizado da mesma forma em todos os vídeos para mantermos uma padronização.

3. Durante as gravações, usar um fone de ouvido com microfone para o áudio ficar melhor.

4. Primeira cena do vídeo (materiais e equipamentos utilizados):

a) posicionar os materiais e equipamentos sobre a mesa, em uma metade da tela (lado direito ou esquerdo). Ao editar o vídeo, colocaremos a lista de materiais por escrito na outra metade da tela. Alternar a posição em cada vídeo para não ficar sempre igual. Deve constar também os resíduos que serão a matéria prima. Esses materiais devem

Revista Extensão \& Cidadania, v. 9, n. 16, p. 95-111, jul./dez. 2021.

ISSN 2319-0566 DOI: 10.22481/recuesb.v9i16.9505 
ser os mesmos que estão na nossa do Google Drive;

b) iniciar a gravação com a seguinte fala: Olá, nesse vídeo construiremos um(a) (nome do instrumento), utilizando como matéria prima resíduos de (resíduos utilizados). Para isso, utilizaremos os seguintes materiais: falar os materiais e equipamentos utilizados.

5. Segunda cena (metodologia):

a) Assistir e memorizar o vídeo original que pesquisamos no YouTube para fazer este instrumento, de forma que você consiga reproduzir a construção do instrumento e gravar tudo de forma organizada, seguindo as mesmas etapas do vídeo original.

b) Neste momento, a mesa da filmagem deve estar vazia para dar a sensação de início de construção. Você estará com os materiais ao seu alcance, ao lado da mesa onde a filmagem está sendo feita e vai pegando os materiais à medida que for necessário.

c) Iniciar a gravação com uma fala do tipo: A primeira etapa da construção desse instrumento consiste em.... (vai gravando o vídeo e narrando o que está fazendo).

6. Terceira cena (resultados e considerações):

a) ao final da gravação, mostrar o instrumento de todos os ângulos, falar quais a sua impressão na construção deste instrumento utilizando resíduos como matéria prima, pontos positivos, negativos ou qualquer outra coisa que ache necessário;

b) testar o instrumento. Poderá ser feito na sequência da fala anterior, mas se for preciso aprender um pouco a usá-lo, pode fazer outro vídeo pequeno depois de aprender o básico de uso do instrumento, testando o mesmo;

c) encerrar o vídeo com uma mensagem de agradecimento e despedida a quem assiste ao vídeo.

7. Na edição do vídeo, fazer o recorte das cenas de forma que o vídeo tenha em média 10 minutos. No início do vídeo, colocar o slide de capa do projeto durante aproximadamente 5 segundos. Quando a fala sobre os materiais utilizados iniciar, inserir também a lista de materiais na forma de texto no vídeo. Nos trechos em que não houver fala, acelerar a cena. Ao final do vídeo, colocar o slide de agradecimentos e créditos durante aproximadamente 5 segundos.

8. Exportar e salvar o vídeo na pasta do projeto no Google Drive. Cada vídeo deve ter o seguinte nome: "Nome_do_instrumento_fabricado.mp4".

Fonte: Elaborado pelo autor.

As artes utilizadas na divulgação do projeto foram elaboradas no Canva (site para criação de design) pelas estudantes em conjunto com o professor, no período de um mês. Todas as imagens geradas no projeto possuíam um padrão de cores e simplicidade de layout de forma

Revista Extensão \& Cidadania, v. 9, n. 16, p. 95-111, jul./dez. 2021. 
passarem todas as informações com o mínimo de poluição visual. A divulgação foi feita nas redes sociais do Campus e dos membros do projeto.

$\mathrm{Na}$ última etapa do projeto, realizou-se três lives de qualificação com a comunidade externa, com o uso da ferramenta de conferência web da Rede Nacional de Ensino e Pesquisa (RNP), pois o IFSC possui licença para uso e, também, pelo fato da RNP permitir o gerenciamento dos participantes de forma mais segura, se comparada com o Google Meet por exemplo. Para cada live, elaborou-se um roteiro, utilizando o modelo do Quadro 2, que foi seguido pelas estudantes, as quais foram as apresentadoras e mediadoras, com exceção da primeira live, que o professor fez a mediação.

\section{Quadro 2 - Modelo de roteiro para live}

\section{Modelo de Roteiro para live}

1) Iniciar com o vídeo institucional: https://www.youtube.com/watch?v=7nWX6DL_x10.

2) Introdução:

- inserir na tela da RNP a arte de divulgação da live do dia;

- abrir a câmera e o áudio e fazer a seguinte fala:

- Boa tarde a todos e a todas que estão aqui conosco. Sejam muito bem-vindos a nossa (primeira, segunda ou terceira) live do projeto de extensão "Qualificação de fabricadores de instrumentos musicais a partir de resíduos sólidos urbanos";

- Meu nome é sou estudante do IFSC, Campus Garopaba e extensionista desse projeto com minha colega sob a coordenação do professor

- na live de hoje abordaremos sobre

- lembrando que as lives são gratuitas e quem se inscrever, vai receber por e-mail um certificado de participação de 5 horas. O link para as inscrições está no chat (Operador da videochamada, colar no chat a seguinte mensagem: Olá pessoal, aqui está o link para a inscrição e obtenção do certificado de participação:

https://forms.gle/c3WbNQNwEo59P4cL6);

- as lives acontecerão sempre nesse mesmo link que está na tela e, também, ao vivo pelo YouTube do Campus Garopaba;

- para as pessoas que queiram interagir conosco por meio de áudio e vídeo, recomendamos entrar na live pelo link que está na tela, já que pelo YouTube a interação se limita ao chat; - após o vídeo vamos abrir um espaço para perguntas troca de saberes e experiências com vocês.

3) Apresentação dos vídeos e interação com o público.

Revista Extensão \& Cidadania, v. 9, n. 16, p. 95-111, jul./dez. 2021.

ISSN 2319-0566ＤOI: 10.22481/recuesb.v9i16.9505 
- Passar os vídeos.

- No final de cada vídeo, convidar o público para interagir, seja com perguntas no chat ou por áudio/vídeo. (Operador da videochamada: ficar verificando o chat da RNP e do YouTube e trazer as perguntas para os mediadores).

4) Finalização

- Colocar a arte de divulgação da próxima live na tela da RNP.

- Fazer a fala de encerramento e agradecimentos: Então por hoje é isso, pessoal, gostaríamos de agradecer a todos que estiveram conosco e convidá-los a participar da próxima live, na próxima , dia às horas para assistirem, em que abordaremos o processo

de fabricação do . Grande abraço e até a próxima live;

- Encerrar a transmissão na RNP e YouTube.

Fonte: Elaborado pelo autor.

Ofereceu-se também certificado de participação para todos que se inscrevessem e participassem das lives. Para a inscrição dos participantes, utilizou-se a ferramenta formulários do Google e para a geração e envio automatizado dos certificados por e-mail, utilizou-se as planilhas do Google com o complemento Autocrat.

\section{Resultados e discussão}

Para executar o projeto conforme planejado, as estudantes precisaram trabalhar em equipe, ter uma boa comunicação, aprender sobre ferramentas de gerenciamento de projetos como o Trello, ferramentas de edição de imagem como o Canva, ferramentas de edição de vídeo, ferramentas do Google (Drive, Meet, Gmail, Agenda, Planilhas, Documentos, Apresentações, Formulários), RNP, além do processo de construção dos instrumentos, portanto há de se destacar, inicialmente, que toda a aprendizagem sobre o uso dessas ferramentas foi construída pelas próprias estudantes ao longo do projeto, com a mediação do professor.

Como resultado da primeira etapa chegou-se a cinco instrumentos possíveis de serem fabricados em casa com algumas adaptações: 1) pandeiro com tampa de balde e lacres de latinhas de alumínio; 2) flauta com cano de PVC e rolha de garrafa; 3) chocalho com garrafa PET e bitucas de cigarro; 4) tambor chinês com lata de sardinha e 5) tambor com balde, fita adesiva e bitucas de cigarro.

Revista Extensão \& Cidadania, v. 9, n. 16, p. 95-111, jul./dez. 2021. 
Na segunda etapa do projeto, produziu-se os 5 vídeos que estão hospedados no canal do YouTube do IFSC, Campus Garopaba: pandeiro (https://youtu.be/HEgnzYeOfXQ); flauta (https://youtu.be/HLSw0MzMv7g); chocalho (https://youtu.be/ac1v14eHTsE); tambor chinês (https://youtu.be/Q4EUpcS-_Us) e tambor de balde (https://youtu.be/2S1L1hvMvzU). A medida em que iam construindo os instrumentos e gravando os vídeos, as estudantes aprendiam sobre o processo, o que permitiu que elas constatassem em algumas situações outras formas de construir ou melhorar aqueles instrumentos. Esses conhecimentos foram compartilhados com a comunidade durante as lives.

A divulgação do projeto na comunidade externa foi realizada através das redes sociais do IFSC de Garopaba (Facebook e Instagram), perfil do Instagram do curso de Gestão Ambiental (https://www.instagram.com/gestaoambiental.ifsc/), redes sociais e grupos WhatsApp dos membros do projeto e dos próprios alunos do curso. Os cartazes criados foram compartilhados diariamente nas semanas que antecederam as lives, iniciando pelo cartaz contendo a programação completa da Figura 3a, seguido pelo da Figura 3b, Figura 3c e, finalmente, o da Figura 3d.

\section{Figura 3 - Cartazes de divulgação utilizados na ação de extensão}

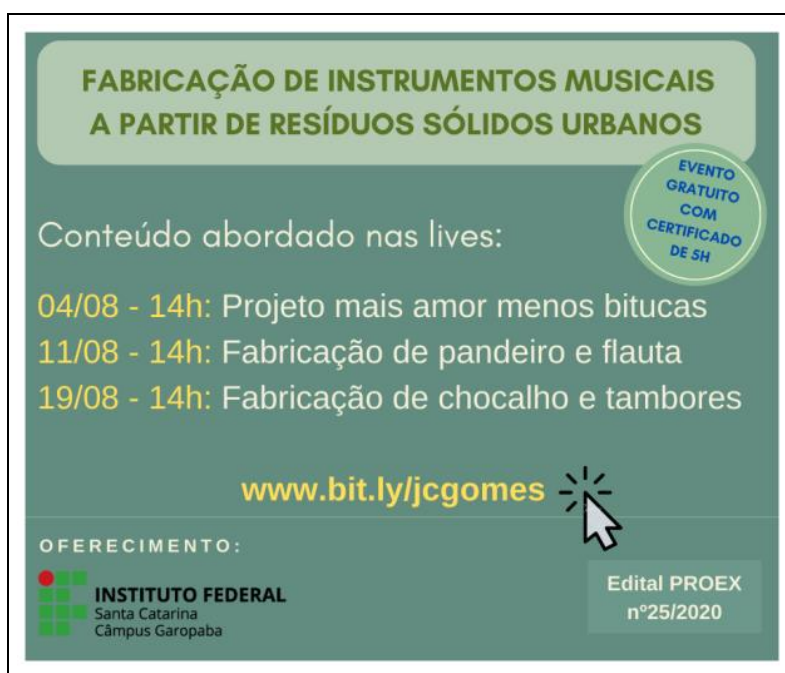

$3 a$

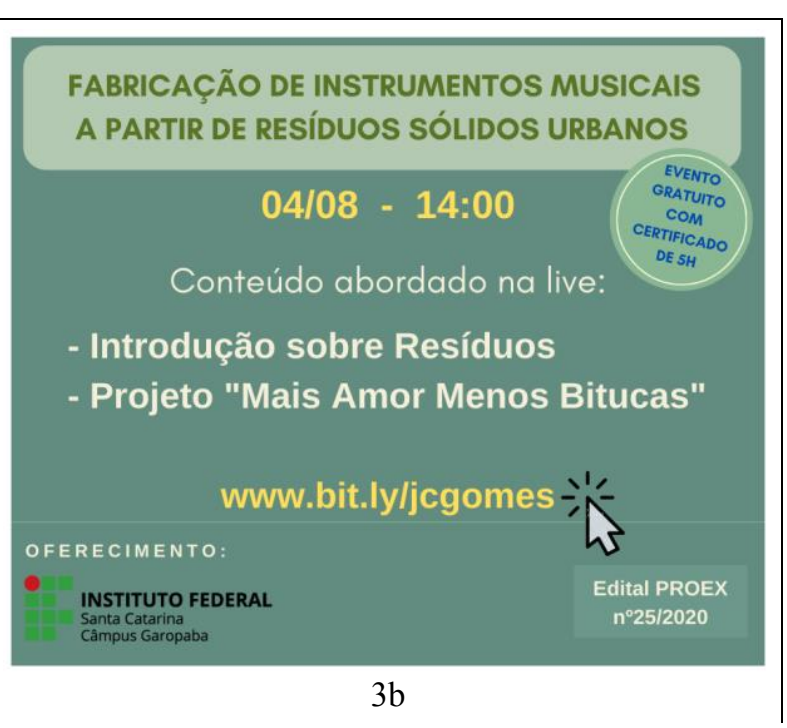

Revista Extensão \& Cidadania, v. 9, n. 16, p. 95-111, jul./dez. 2021.

ISSN 2319-0566 DOI: 10.22481/recuesb.v9i16.9505 


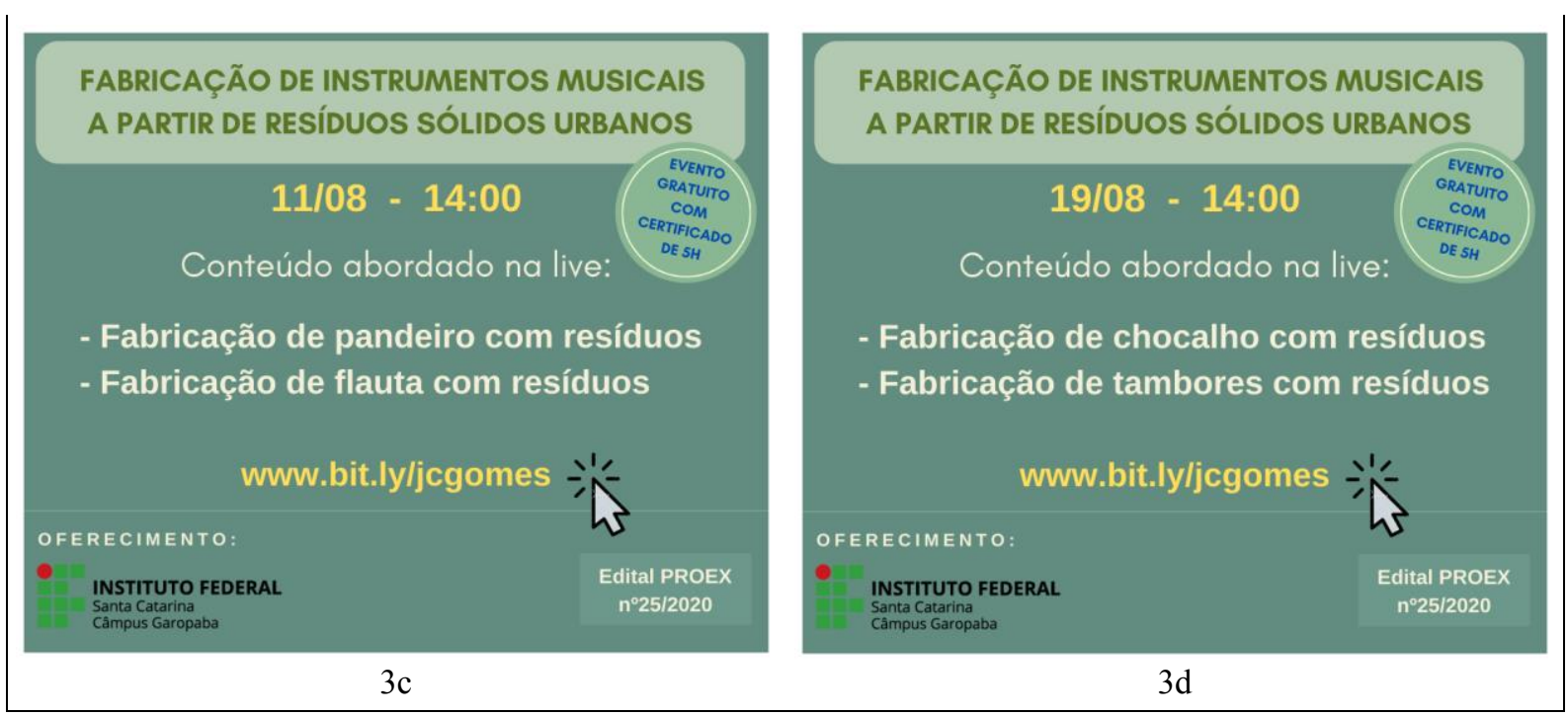

Fonte: Elaborada pelo autor.

Os cartazes eram acompanhados do texto modelo do Quadro 3 para contextualizar o projeto e, ao mesmo tempo, atribuir uma característica mais humanizada ao convite.

\section{Quadro 3 - Texto modelo de divulgação das lives do projeto}

Convidamos toda a comunidade para participar das lives do Projeto de Extensão Fabricação de instrumentos musicais a partir de resíduos sólidos urbanos, promovido no IFSC, Campus Garopaba. As lives podem contribuir para jovens e adultos terem ideias de como trabalhar a reutilização do lixo urbano e, ao mesmo tempo, como uma campanha antitabagismo e de conscientização da importância da preservação das nossas praias.

O espaço também servirá para a troca de saberes e experiências, podendo qualquer participante interagir por chat/vídeo seja com perguntas seja com relato de suas experiências. O evento terá certificado de participação de 5 horas. O link para a inscrição será compartilhado durante as lives.

Link para as lives: www.bit.ly/jegomes

Tutorial rápido de como acessar a plataforma das lives: www.bit.ly/tutorial-RNP

Venha participar, contamos com a sua presença.

Fonte: Elaborado pelo autor.

A realização das lives para a qualificação da comunidade externa foi a última etapa do projeto. Realizou-se 3 lives, uma por semana para permitir que os participantes se organizassem e não tivessem outras atividades do dia-dia comprometidas.

Esse projeto de extensão foi concebido a partir de uma iniciativa da comunidade na região central de Garopaba, chamada "Mais amor menos bitucas por favor", que tinha como

Revista Extensão \& Cidadania, v. 9, n. 16, p. 95-111, jul./dez. 2021.

ISSN 2319-0566ＤOI: 10.22481/recuesb.v9i16.9505 
objetivo promover a coleta seletiva das "bitucas de cigarro" para lhes dar destino final adequado e, ao mesmo tempo, realizar campanha antitabagismo e de preservação das praias com os jovens do município. Por isso, utilizou-se no projeto parte das bitucas coletadas pela iniciativa comunitária.

A primeira live (https://youtu.be/YawPrShCcsU) foi inteiramente dedicada a apresentar o projeto e a iniciativa "Mais amor menos bitucas por favor", através de um bate-papo descontraído, mas carregado de mensagens de amor e respeito com todos os seres vivos e com o ambiente abiótico. Nessa live, o professor foi o mediador para que as estudantes pudessem aprender por observação o papel que exerceriam nas lives seguintes.

Na segunda live (https://youtu.be/iceXmuyBpqA), as estudantes apresentaram os vídeos da fabricação do pandeiro e da flauta e, por último, a terceira live (https://youtu.be/J_RbsV9Bo4), os vídeos do chocalho, tambor chinês e tambor de baldes. As estudantes se revezaram nas apresentações dos vídeos produzidos, de forma que logo após a apresentação de cada vídeo, era aberto o espaço para a troca de saberes, experiências e interação com o público que estava fazendo perguntas nos chats do YouTube e RNP. Nesse momento, as estudantes participavam juntas, faziam o compartilhamento daquilo que haviam aprendido durante a construção dos instrumentos e davam dicas de modo a permitir a otimização da construção dos instrumentos. Nessas lives, o professor e a CERE do Campus deram suporte às estudantes como operadores das videochamadas, transmitindo-as ao vivo para o YouTube do Campus de Garopaba, controlando os chats e realizando intervenções quando necessário.

De forma geral, houve boa interação com o público que assistia as lives através do chat YouTube e RNP. Ao todo, foram produzidos 8 vídeos que podem ser visualizados na playlist (https://youtube.com/playlist?list=PLEgUtnEeCfYEDNzjC_i_GGWlh81kPW7tU) do projeto. Durante as lives, o pico simultâneo médio foi de 30 pessoas (levando em consideração os participantes da RNP e YouTube) e o número de reprodução das transmissões variou de 30 a 60, estando de acordo com a expectativa que se tinha. Até o momento da conclusão deste trabalho os 8 vídeos somavam 486 visualizações, porém o fato de os vídeos estarem disponíveis online significa que mais pessoas poderão se qualificar ao passar do tempo.

Levando-se em consideração que os assuntos abordados no projeto de extensão (gestão de resíduos sólidos) também são conteúdos trabalhados em sala de aula, esse tipo de ação de extensão online é considerado de grande relevância para os cursos da área ambiental do Campus, já que os projetos ficam registrados em playlists como uma verdadeira base de dados

Revista Extensão \& Cidadania, v. 9, n. 16, p. 95-111, jul./dez. 2021.

ISSN 2319-0566 DOI: 10.22481/recuesb.v9i16.9505 
possível de voltar à sala de aula para enriquecer ainda mais o processo de construção do conhecimento.

Em outras palavras, as estudantes utilizaram os conhecimentos produzidos em aula, realizaram pesquisas utilizando alguns princípios do método científico e elaboraram produtos de extensão que foram compartilhados com a sociedade buscando a articulação entre os saberes e a interação dialógica, perfazendo assim a tríade ensino, pesquisa extensão vista na Figura 4 a seguir.

Figura 4 - Tríade ensino, pesquisa e extensão

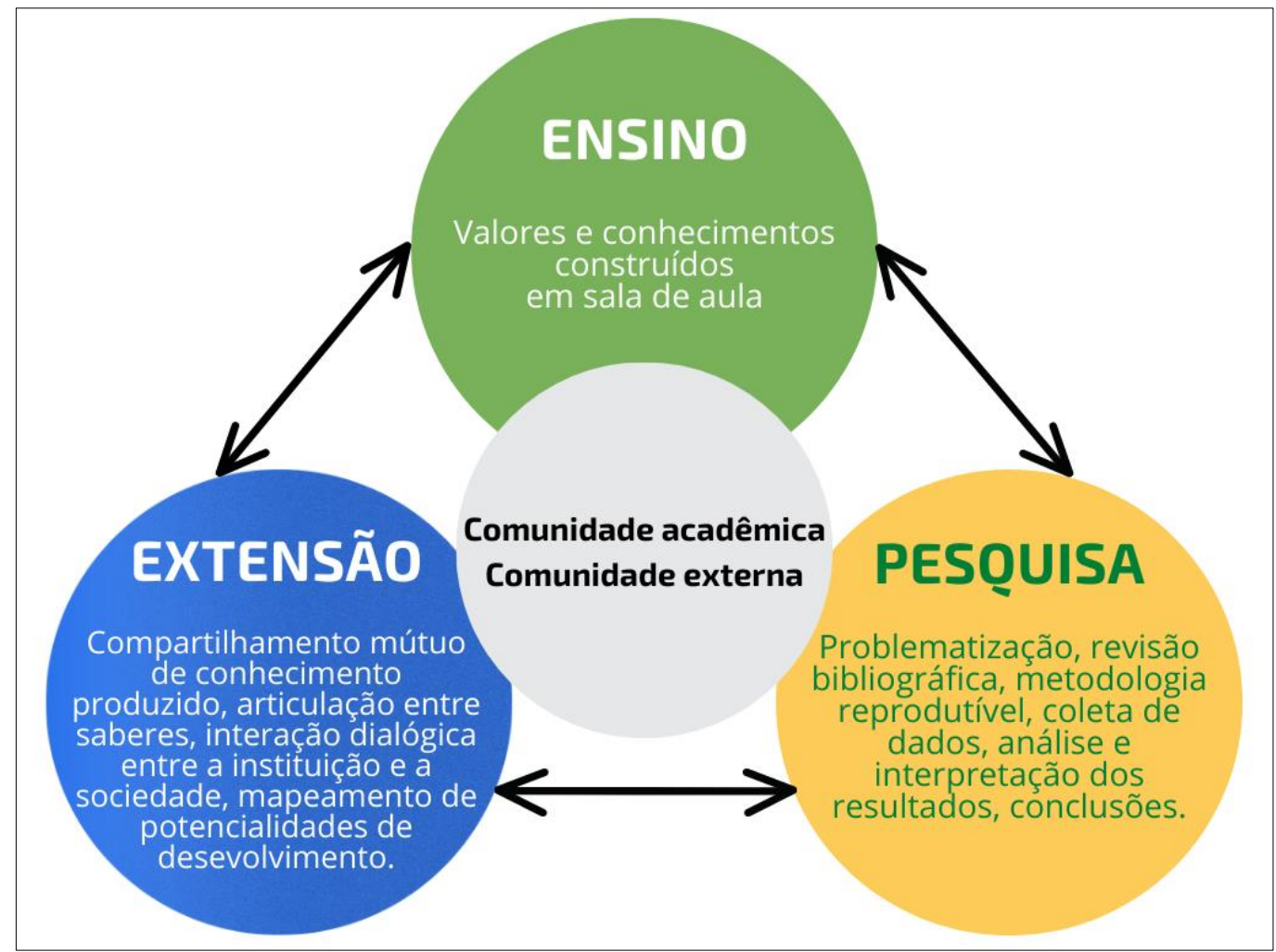

Fonte: Elaborada pelo autor.

Entretanto essa tríade não se limita a um ciclo com um único sentido direcional, a tríade é dinâmica, podendo um elemento interagir com o outro em prol da comunidade acadêmica e da comunidade externa. Ou seja, o ensino pode identificar problemas a serem respondidos por meio da pesquisa ou conhecimentos a serem compartilhados com a sociedade através da extensão, a pesquisa pode gerar conhecimentos para a sala de aula e/ou a serem compartilhados com o público externo e a extensão pode detectar a necessidade de realizar pesquisa e/ou

Revista Extensão \& Cidadania, v. 9, n. 16, p. 95-111, jul./dez. 2021.

ISSN 2319-0566 DOI: 10.22481/recuesb.v9i16.9505 
apresentar seus resultados em sala de aula para estudo de seus produtos. Por isso, afirma-se que a relação entre o ensino, a pesquisa e a extensão são indissociáveis e imprescindíveis para se manter o padrão de qualidade no âmbito da educação profissional e tecnológica.

\section{Considerações finais}

Esse projeto de extensão foi submetido e aprovado meses antes das atividades presenciais serem suspensas, no início de 2020, portanto ele havia sido planejado para ser executado de forma presencial. O maior desafio enfrentado foi adaptá-lo para o contexto não presencial e manter a motivação das estudantes bolsistas durante o período, pois a pandemia trouxe situações adversas que não favoreceram a execução do projeto.

O planejamento, a organização e o diálogo constante entre a equipe foram fundamentais para que o projeto conseguisse atingir seus objetivos e no contexto atual das atividades não presenciais o uso de tecnologias digitais para o gerenciamento do projeto foi essencial.

Durante a execução do projeto, o professor realizou a mediação necessária para que as estudantes aprendessem sobre cada tecnologia digital que utilizavam e na medida em que utilizavam essas tecnologias de forma integrada no cumprimento das metas estabelecidas, sentiam-se mais confiantes. Isso pode ser constatado durante um encontro virtual ao final do projeto em que uma das estudantes relatou que, no início do projeto quando o professor propôs a forma de trabalho, ela pensava que ia ser mais difícil do que foi e concluiu dizendo que foi muito tranquilo executar o projeto. Portanto não basta apenas dispor de tecnologias digitais, deve-se saber utilizá-las e aplicá-las ao contexto, sobretudo, mantendo o planejamento, a organização e o diálogo constante para que se tenha sucesso.

$\mathrm{O}$ amadurecimento das estudantes ao longo do projeto foi muito perceptível, pois onde tinha-se inicialmente duas pessoas tímidas em relação à certeza de conseguirem atingir os objetivos, no momento das lives passou-se a ter duas pessoas empoderadas de conhecimentos e se sentindo aptas a compartilhar e dialogar com a sociedade, ao vivo na Internet. O retorno foi instantâneo através dos comentários, elogios e mensagens de carinho que as estudantes receberam no chat do YouTube e RNP durante as lives.

Ao todo foram produzidos 8 vídeos, sendo 3 lives e 5 cinco vídeos de construção de instrumentos musicais reutilizando resíduos sólidos. As lives tiveram um pico simultâneo

Revista Extensão \& Cidadania, v. 9, n. 16, p. 95-111, jul./dez. 2021.

ISSN 2319-0566 DOI: 10.22481/recuesb.v9i16.9505 
médio de 30 pessoas e até o momento da conclusão deste trabalho os 8 vídeos somavam 486 visualizações, indicando que, com o passar do tempo, mais pessoas se qualificarão no assunto.

Nesse sentido, os resultados obtidos foram altamente positivos e demonstraram que é imprescindível o olhar institucional para o melhoramento de sua infraestrutura e capacitação contínua da comunidade acadêmica no uso de metodologias ativas e tecnologias digitais.

\section{Referências}

ABRELPE. Panorama dos Resíduos Sólidos no Brasil: 2020. São Paulo, 2020. Disponível em: https://abrelpe.org.br/panorama/. Acesso em: 31 jul. 2021.

BRASIL. Lei no 12.305, de 2 de agosto de 2010. Institui A Política Nacional de Resíduos Sólidos; altera a Lei n ${ }^{\circ}$ 9.605, de 12 de fevereiro de 1998; e dá outras providências. Brasília, DF: Presidência da República, 2010. Disponível em: http://www.planalto.gov.br/ccivil_03/_ato2007-2010/2010/lei/112305.htm. Acesso em: 25 ago. 2021.

BRASIL. Plano Nacional de Resíduos Sólidos. Brasília, 2011. Disponível em: http://www.mma.gov.br/estruturas/253/_publicacao/253_publicacao02022012041757.pdf. Acesso em: 25 mar. 2019.

CASTAMAN, A. S.; BORTOLI, L. A. DE. Metodologias ativas na educação profissional e tecnológica. Educação, v. 10, n. 3, p. 145-156, jun. 2021.

COSENZA, J. P.; ANDRADE, E. M.; ASSUNÇÃO, G. M. Economia circular como alternativa para o crescimento sustentável brasileiro: análise da Política Nacional de Resíduos Sólidos. Revista Gestão Ambiental e Sustentabilidade - GeAS, v. 9, n. 1, p. 1-30, 2020, e16147. Disponível em: https://doi.org/10.5585/geas.v9i1.16147. Acesso em: 25 mar. 2019.

FERRARINI, R.; SAHEB, D.; TORRES, P. L. Metodologias ativas e tecnologias digitais: Revista Educação em Questão, v. 57, n. 52, p. 1-30, mar. 2019.

GALLO, A. C. P.; GUENTHER, M. Reciclagem e reutilização de resíduos: um projeto socioambiental desenvolvido na educação de jovens e adultos (EJA) do SESC Santo Amaro, Recife (PE). Revista Brasileira de Educação Ambiental - RevBEA, v. 10, n. 4, p. 11-23, dez. 2015.

GAROPABA. Coleta de lixo. Município de Garopaba, 2021. Disponível em: https://www.garopaba.sc.gov.br/cms/pagina/ver/codMapaItem/108072. Acesso em: 31 jul. 2021.

GAROPABA. Plano Municipal de Saneamento Básico de Garopaba: volume 1: versão final do Plano Municipal de Saneamento Básico de Garopaba. 2012. Disponível em:

Revista Extensão \& Cidadania, v. 9, n. 16, p. 95-111, jul./dez. 2021.

ISSN 2319-0566 DOI: 10.22481/recuesb.v9i16.9505 
https://static.fecam.net.br/uploads/344/arquivos/639774_121_anexo_volume_i_versao_final_ pmsb.pdf. Acesso em: 31 jul. 2021.

GOMES, J. da C. Formação de multiplicadores para reciclagem de resíduos orgânicos por meio da compostagem em tempos de pandemia. Revista ELO - Diálogos em Extensão, v. 10, abr. 2021.

IBGE. Cidades: Garopaba SC. 2020. Disponível em: https://cidades.ibge.gov.br/brasil/sc/garopaba/panorama. Acesso em: 31 jul. 2021.

MORAN, J. Mudando a educação com metodologias ativas - Educação Transformadora. 2015. Disponível em: http://www2.eca.usp.br/moran/wpcontent/uploads/2013/12/mudando_moran.pdf. Acesso em: 25 ago. 2021.

OLIVEIRA, A. C. et al. Educação ambiental através da música: a experiência da reutilização do lixo na construção de instrumentos musicais. 2007. Disponível em: https://www.academia.edu/31930780/educação_ambiental_através_da_música_a_experiência _da_reutilização_do_lixo_na_construção_de_instrumentos_musicais?bulkDownload=thisPap er-topRelated-sameAuthor-citingThis-citedByThis-secondOrderCitations\&from=cover_page. Acesso em: 25 ago. 2021.

PORTUGAL. Resolução do Conselho de Ministros 190-A/2017, 2017-12-11 - DRE. 2017. Disponível em: https://dre.pt/web/guest/pesquisa/-/search/114337039/details/normal?l=1 . Acesso em: 25 ago. 2021.

SALVADOR, F. L. R. Análise das etapas de um plano de recuperação de área degradada (PRAD) aplicada para um antigo lixão no município de Garopaba. Florianópolis: Ed. da Universidade Federal de Santa Catarina, 2012. Disponível em:

https://repositorio.ufsc.br/bitstream/handle/123456789/126177/TCC_Fabio_Ramos_Formatad o.pdf?sequence=1 Acesso em: 31 jul. 2021.

TURRA, A. et al. Lixo nos mares: do entendimento à solução. São Paulo: Ed. do Instituto Oceanográfico da Universidade de São Paulo, 2020. Disponível em:

http://catedraoceano.iea.usp.br/lixonosmares/. Acesso em: 25 ago. 2021.

Recebido: 15.09.2021

Aceito: 29.10.2021

(a)

EY This work is licensed under a Creative Commons Attribution 4.0 International License.

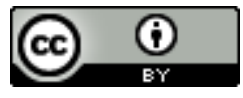

Este trabalho está licenciado com uma Licença Creative Commons - Atribuição 4.0

Internacional.

Revista Extensão \& Cidadania, v. 9, n. 16, p. 95-111, jul./dez. 2021.

ISSN 2319-0566 DOI: 10.22481/recuesb.v9i16.9505 